\title{
$\angle$ Research Square \\ Factors influencing desired number of children among Ethiopian women: Application of count regression models.
}

Habitu Liyew Molla

Debark University

Essey Kebede Muluneh ( $\nabla$ esseykebede@gmail.com )

Bahir Dar University https://orcid.org/0000-0002-2469-5009

\section{Research article}

Keywords: Desired number of children, statistical weight, EDHS, Count regression models, multilevel analysis

Posted Date: December 1st, 2019

DOI: https://doi.org/10.21203/rs.2.17780/v1

License: (c) (i) This work is licensed under a Creative Commons Attribution 4.0 International License.

Read Full License 


\section{Abstract}

Background: Desired family size, the number of children wanted in one's lifetime, is one of the major factors influencing the population dynamics. Knowledge of factors influencing the desired family size is crucial in regulating the population growth. This study assesses the desired family size and its determinants among Ethiopian women.

Methods: The study was based on the 2016 Ethiopian Demographic and Health Survey (EDHS) data. A total of 13,941 women with complete information were considered in the study. Count regression models, a family of generalized linear models, were used to identify determinant factors for the desired number of children among women in Ethiopia.

Results: Results showed that the average number of children per women was 4.5. The highest average was recorded in Somali region (10.58) and the lowest in Addis Ababa city administration (3.56). The random intercept negative binomial regression model was found to be the most appropriate model for the data. Women's age, household head, contraception using, wealth index, women's education, religion, marital status, husband's work, family size and age at first marriage were significantly associated with the desired number of children by women at reproductive age. The study also showed that there was significant regional variation in desired number of children among Ethiopian women.

Conclusions: Variables such as women's age and family size were positively associated with the desired number of children by women at reproductive age while age at first marriage, contraception using, wealth index and women's education were negatively associated with the desired number of children by women. Women who attained higher level of education preferred small family size compared to women with no formal education. Desire for children was high among mothers from rural areas, women in the poorest economic level and woman having no work. Keywords: Desired number of children, statistical weight, EDHS, Count regression models, multilevel analysis.

\section{Background}

Continued rapid population growth remains a challenge for sustainable development, putting more pressure on already strained resources. Resource poor countries will be more seriously affected by unplanned population growth. More than half of the projected increase in the global population up to 2050 will be concentrated in just nine countries, five of which including Ethiopia are in Africa. With a projected addition of over one billion people, countries of sub-Saharan Africa could account for more than half of the growth of the world's population between 2019 and 2050 [1]. With an estimated population of 112 million and projected to reach 205 million by 2020, Ethiopia is the second most populated nation in Africa and ranks twelfth in the world [2].

Several factors contribute for the rapid growth in population size. The desire to bear more children is one main reason. Thomson [3] refers to preferred or desired family size as the number of children wanted in one's lifetime. Desire for children is a biological urge and women in every part of the globe, be it a 
developed nation like America or a poor nation like Ethiopia, all need to bear children. Eighty six percent of Americans aged 45 or older have had children, and nine in 10 of these say they would have children if they had to "do it over again." [4]. Motherhood was an important component of married women's identity and important for women's social status. Marginalized women, including women living with HIV, consider motherhood as a means to be valued by the woman herself and within her social or familial context $[3$, 5-8].

Ethiopia has predominantly rural based society whose livelihood depends on individual level subsistence level farming. In this kind of set up children are expected to help their parents in their efforts to feed their families. The high level of child mortality in the nation, where 1 in 15 children dies before reaching age 5 , and 7 in 10 of the deaths occur during infancy, also plays an important role to determine the desired family size. Even though women's desired family size has declined in the last ten years, from 5.3 children in 2000 to 4.5 children in 2016, a large proportion of Ethiopians, regardless of their number of living children, still want to have four or more children [9]. This study was aimed at identifying factors associated to the desired number of children among Ethiopian women in the reproductive age.

\section{Methods}

\section{Data for the study}

The data for the present study was taken from the 2016 Ethiopian Demographic and Health Survey (EDHS), a nationally representative survey that was conducted under the authority of the Ethiopian Central Statistical Agency in collaboration with the Federal Ministry of Health (FMoH) and the Ethiopian Public Health Institute (EPHI), with technical assistance from International Consultancy Fund (ICF). The survey was conducted from January 18,2016 , to June 27,2016 , based on a nationally representative sample that provides estimates at the national and regional levels and for urban and rural areas.

The survey target groups were women aged 15-49 and men aged 15-59 in randomly selected households across Ethiopia. A total of 18,008 households were selected using two-stage stratified cluster sampling method of which 17,067 were occupied. Of the occupied households, 16,650 were successfully interviewed, yielding a response rate of $98 \%$. After excluding women who gave non-numerical answers such as "It depends on God", "As many as I can", "Depending on my husbands will”, a total of 13,941 women having numeric response for desired number of children were considered in this study. These women were asked questions on the background characteristics such as region, age, education level, household headship, living children, contraception using, place of residence, wealth index, work, religion, marital status, family size, age at first marriage, husbands education level and husbands work.

\section{Data analysis}

When the response or dependent variable is a count which can take on non-negative integer values $(0,1,2$ ...), it is appropriate to use non-linear models based on non-normal distribution to describe the 
relationship between the dependent variable and a set of predictor variables[10]. For count data, the standard framework for explaining the relationship between the outcome variable and a set of explanatory variables includes the Poisson and negative binomial regression models [11].

Poisson distribution is the most common probability model for discrete data with observations assumed to have a constant rate of occurrence amongst individual units with the property of equal mean and variance[12]. However, mean and variance may not be equal in practice. An extension of the Poisson distribution which allows for unequal mean and variance is the negative binomial distribution [13]. These two models are a family of generalized linear models (GLM).

Data sets with a nesting structure that include unexplained variability at each level of nesting are usually not adequately represented by single level regression [14].The best approach to the analysis of multilevel data is an approach that represents within-group as well as between-group relations within a single analysis, where group refers to the units at the higher levels of the nesting hierarchy [14]. In this study since individual women are nested in regions, two-level count regression model where women are considered level- 1 and the regions are level- 2 was used.

Sampling weights have also been considered when fitting models to this survey data. The design weights are used either when we want the survey statistics to be representative of the underlying population or when we want to compensate for over or under-sampling of specific cases or for disproportionate stratification. For computing design weights, we must know the sampling fraction, which is usually the over-sampling or the under-sampling amount for a given group or area. Thus, for instance, the unweighted samples in a survey over or under-represent people of certain areas or size of households, such as those in larger households. The design

weight corrects for differences in selection probabilities, thereby making the sample more representative of a true sample of individuals in a country. The design weights were computed as normalized inverse of the inclusion probabilities [15].

Due to the non-proportional allocation of the samples to the different regions and their urban and rural areas and the possible differences in response rates, sampling weights must be used in all analyses using the 2016 EDHS data to ensure that the survey results at both the national and domain levels were representative. Since the 2016 EDHS sample is a two-stage stratified cluster sample, sampling weights were based on sampling probabilities separately for each sampling stage and each cluster.

\section{Results}

A total of 13,941 women were included in the study. Of all women studied, $76 \%$ live in rural areas where contraceptives are rarely available and as a result only one-fourth of the women in the study population were contraceptive users. More than three fourth of the households were headed by males. One third of the women were not employed and nearly half $(45 \%)$ have no education. The mean desired number of children per women was 4.5 and the corresponding standard deviation was 2.7 children (variance 7.29 ) 
per women in Ethiopia showing that the distribution of desired family size was over-dispersed (Details can be found in Table 1).

Figure 1 shows that the distribution of the desired number children per women in the reproductive age group is positively skewed and does not have normal distribution suggesting the use of non-normal error models. A family of count regression models such as Poisson and negative binomial models are better alternatives for the data.

Table 2 shows that the ratio of the Deviance and Pearson Chi-square statistic to their corresponding degrees of freedom were greater than one, indicating over dispersion in the data. Therefore negative binomial regression model was superior over the Poisson regression model [16]. The likelihood ratio test ( $p$-value<0.001) also indicates the existence of heterogeneous random effect and hence multilevel negative binomial regression model could provide a good fit to the data (Table 3).

The results in Table 4 displaying a comparison of families of negative binomial model showed that the values of log likelihood, AIC and BIC were smallest for the random intercept model suggesting that the random intercept multilevel negative binomial model better fits the given data.

The results from the random intercept model given in Table 5, showed that the level-two (region level) variance of the random intercept $\delta u 02=0.0083395$ was found to be significant indicating that the number of desired children per mother differs among regions. The results of multilevel negative binomial regression of random intercepts model showed that women's age, household head, contraception, wealth index, women's education, religion, marital status, family size and age at first marriage were statistically significant predictors of the desired number of children. On the other hand, husband's education, husband's work, place of residence, women's employment status and number of living children were not statistically significant predictors for the outcome variable.

The parameters of observed variables can be interpreted much the same way as those from the ordinal model. The estimated coefficients for all age groups are positive showing that the desired number of children increases with age of the women. The expected desired number of children for a women aged 45-49 was $30.3 \%$ (IRR = 1.303792) which is higher than the expected number of desired children that women aged 15-19 would like to have controlling all other variables in the model and random effect at level two. The coefficient for the contraception use is negative and statistically significant, showing that the expected desired number of children for contraceptive user women was $8.1 \%(1-I R R=0.0811125)$ less than a non-user women. Poor mothers tend to have more desire for children compared to relatively wealthy mothers.

Education plays a vital role in deciding the desire for children. In this study women's education level was negatively associated with the desired number of children. Thus, primary educated women's are expected to have $91.2 \%$ (IRR $=0.9121705)$ fewer desired number of children than uneducated women and higher educated women's are expected to have $93.7 \%(I R R=0.9375662)$ fewer desired number of children than the illiterate women. 
Women following Protestant, Muslim, Traditional and Other religions had higher desired number of children as compared to women following Orthodox Christian religion (14.2\%, 18.8\% 18.5\% and $47.4 \%$ respectively more than women following Orthodox). Married and separated women have respectively $34.4 \%$ and $19.7 \%$ more desired number of children than single women. As may be expected desired family size decreases with age at first marriage. Women getting married at later ages had less desire for more children than those married at younger ages.

\section{Discussion}

The present study was based on data from the 2016 Ethiopian Demographic and Health Survey (EDHS), a nationally representative survey that was conducted under the authority of the Ethiopian Central Statistical Agency in collaboration with the Federal Ministry of Health $(\mathrm{FMoH})$ and the Ethiopian Public Health Institute (EPHI). A total of 13,941 women of age between 15 and 49 from the 2016 EDHS data were included in the study.

The study explores the determinants of desired number of children an Ethiopian woman of reproductive age (15-49) would like to have in her lifetime using count regression models. The mean desired number of children by an Ethiopian women in her reproductive age was 4.5 showing a slight increase from the 2011 EDHS report. The expected desired number of children was higher in aged women as compared to younger women. The results of some other studies indicated that younger women have higher likelihood of having high desire for children through her life time than older woman $[17,18]$. Desired number of children shows a decline with the increase in age at marriage of the mother. Similar findings have also been reported by Uddin and his friends in their study based on Bangladesh demographic and health survey of 2007 [19].

More educated woman tend to have smaller desired number of children as compared to less educated women. This finding is in line with many previous literatures in different settings [19-22]. This result is logical in the Ethiopian context in the sense that less educated women were mostly not employed and spend most of their time looking after their children as housewives which again makes them comfortable to still have more children. It may also be that most of the women included in this study reside in rural areas where children are considered as assets. Another study in Guatemala however reported that education was positively associated with the desire for another child [23].

The findings of this study showed that the expected desired number of children was high among large family size households than households with small family size. This result was consistent with the study by $[20,24]$ showing that women having large family size were more likely to desire for additional children than those who had small family size. This result is still expected in view of the education level and place of residence of the women discussed above.

Husband's education is not important predictor for the desire of children. Similar result has been observed in a study in Bangladesh [19]. It seems illogical as husbands have significant role in making decisions on the number of children in their family, particularly in the Ethiopian context where husbands are dominant. 
However it may be that since three-fourth of the women studied were from rural areas and that in rural areas both husbands and wives more or less have similar education level and social set ups which makes them share same views on the number of their children.

Strong inverse relationship ( $\mathrm{p}$-value<0.0001) was found between the desire for more children and contraception, which is logical since women who need to have more children will not use contraception.

\section{Conclusions}

This study was based on a nationwide large sample demographic and survey conducted by the Ethiopian Statistical Agency. The study has empirically investigated and identified the determinants of the desired number of children by Ethiopian women. The multilevel negative binomial regression model analysis identified that a large degree of heterogeneity in desired number of children per mother was observed among regions of Ethiopia. The random intercept model identified that variables such as women's age, household head, religion, marital status and family size were positively associated with the desired number of children by women during their reproductive age while age at first marriage, contraception, wealth index and women's education were negatively associated with the desired number of children by women at reproductive age.

Education and wealth index play vital role in deciding on the number of children a family wants to have. Women with little or no formal education and earning less income tend to have more desire for children. The desire to limit the number of children increases with age at first marriage. To halt the continuing rapid population growth in a resource poor country like Ethiopia, educating women and engaging them in income generating activities should be the among priority policy agendas.

\section{Abbreviations}

EDHS: Ethiopian Demographic and Health Survey; GLM: Generalized linear models; FMoH: Federal Ministry of Health; EPHI: Ethiopian Public Health Institute; ICF: International Consultancy Fund; AIC: Akaike Information Criteria; BIC: Bayesian Information Criteria

\section{Declarations}

Ethics Approval and Consent to Participate: Not Applicable

Consent to publication: This manuscript has not been published elsewhere and is not under consideration in any other journal.

Availability of data and materials: The data used in this study can be obtained on the EDHS website Competing Interests: The authors declare that they have no conflict of interests.

Funding: No fund was obtained for the study. 
Authors' Contributions: HLM and EKM conceived the study, HLM analyzed the data, HLM and EKM interpreted the results and drafted the manuscript. EKM finalized the manuscript to the present form. All authors have read and approved the manuscript.

Acknowledgements: The authors acknowledge the Ethiopian Central Statistics Agency (CSA) for providing the data.

\section{Author Details}

${ }^{1}$ Lecturer of Statistics at Bebark University, Debark, Ethiopia.

${ }^{2}$ Associate Professor of Statistics at Bahir Dar University, Bahir Dar, Ethiopia.

\section{References}

1.United Nations, D.o.E. and P. D. Social Affairs, World Population Prospects 2019: Highlights. 2019.

2.Pison, G., The population of the world (2019). Population \& Sociétés, 2019(8): p. 1-8.

3.Thomson, E., Family size preferences. 2015.

4.Newport, F. and J. Wilke, Desire for children still norm in US. Gallup News. Retrieved from http://news. gallup. com/poll/164618/desire-children-norm. aspx, 2013.

5.Cernigliaro, D., et al., Factors related to fertility desire among female sex workers living with HIV in the Dominican Republic. BMC women's health, 2018. 18(1): p. 117.

6.Cooper, D., et al., "Life is still going on": reproductive intentions among HIV-positive women and men in South Africa. Social science \& medicine, 2007. 65(2): p. 274-283.

7.Melaku, Y. A., et al., Fertility desire among HIV-positive women in Tigray region, Ethiopia: implications for the provision of reproductive health and prevention of mother-to-child HIV transmission services. BMC women's health, 2014. 14(1): p. 137.

8.Wanyenze, R. K., et al., Fertility desires and unmet need for family planning among HIV infected individuals in two HIV clinics with differing models of family planning service delivery. BMC women's health, 2015. 15(1): p. 5.

9.Ethiopia, Ethiopia Demographic and Health Survey, 2016. 2012: ICF International, c entral Statistical Agency, uly 2017.

10.Karazsia, B. T. and M. H. Van Dulmen, Regression models for count data: Illustrations using longitudinal predictors of childhood injury. Journal of pediatric psychology, 2008. 33(10): p. 1076-1084. 
11.Gardner, W., E. P. Mulvey, and E. C. Shaw, Regression analyses of counts and rates: Poisson, overdispersed Poisson, and negative binomial models. Psychological bulletin, 1995. 118(3): p. 392.

12.Dobson, A. J. and A. Barnett, An introduction to generalized linear models. 2008: CRC press.

13.Hilbe, J. M., Negative binomial regression. 2011: Cambridge University Press.

14.Hox, J. J., M. Moerbeek, and R. van de Schoot, Multilevel analysis: Techniques and applications. 2010: Routledge.

15.Johnson, D. R., Using weights in the analysis of survey data. Population research institute, Department of Sociology, Pennsylvania state university, 2008.

16.Yaacob, W. F. W., M. A. Lazim, and Y. B. Wah. A practical approach in modelling count data. in Proceedings of the Regional Conference on Statistical Sciences. Malaysia. 2010.

17.Dudgeon, M. R. and M. C. Inhorn, Men's influences on women's reproductive health: medical anthropological perspectives. Social science \& medicine, 2004. 59(7): p. 1379-1395.

18.Greene, M. E., Changing women and avoiding men gender stereotypes and reproductive health programmes. IDS bulletin, 2000. 31(2): p. 49-59.

19.Uddin, M., K. Bhuyan, and S. S. Islam, Determinants of desired family size and children ever born in Bangladesh. 2011.

20.Puurbalanta, M. R. and W. Aselisewine, Poisson Regression Analysis of Ideal Family Size. Imperial Journal of Interdisciplinary Research, 2016. 2(12).

21.Bhargava, A., Desired family size, family planning and fertility in Ethiopia. Journal of biosocial science, 2007. 39(3): p. 367-381.

22.Dibaba, Y., Factors influencing women's intention to limit child bearing in Oromia, Ethiopia. Ethiopian Journal of Health Development, 2009. 23(1).

23.Pebley, A. R., H. Delgado, and E. Brinemann, Fertility desires and child mortality experience among Guatemalan women. Studies in family Planning, 1979. 10(4): p. 129-136.

24.Adhikari, R., Demographic, socio-economic, and cultural factors affecting fertility differentials in Nepal. BMC pregnancy and childbirth, 2010. 10(1): p. 19.

\section{Tables}

Table 1 Socio demographic characteristics of Ethiopian women, EDHS 2016. 


\begin{tabular}{|c|c|c|c|c|c|}
\hline Variable & Category & Mean & Std. Dev. & Obs. & Percent \\
\hline Total desired children & & 4.45 & 2.76 & 13941 & \\
\hline \multirow[t]{7}{*}{ Women's age } & $15-19$ & 3.58 & 2.34 & 3247 & 22.76 \\
\hline & $20-24$ & 3.91 & 2.24 & 2676 & 18.49 \\
\hline & $25-29$ & 4.39 & 2.51 & 2537 & 18.95 \\
\hline & $30-34$ & 4.78 & 2.72 & 1950 & 14.45 \\
\hline & $35-39$ & 5.30 & 3.09 & 1655 & 11.90 \\
\hline & $40-44$ & 5.67 & 3.30 & 1070 & 7.59 \\
\hline & $45-49$ & 5.66 & 3.46 & 806 & 5.86 \\
\hline \multirow[t]{2}{*}{ Household head } & Male & 4.51 & 2.75 & 9651 & 76.24 \\
\hline & Female & 4.28 & 2.80 & 4290 & 23.76 \\
\hline \multirow[t]{2}{*}{ Living children } & No living child & 3.56 & 2.19 & 5166 & 35.02 \\
\hline & Living child & 4.93 & 2.91 & 8775 & 64.98 \\
\hline \multirow[t]{2}{*}{ Contraception using } & Not Using & 4.50 & 2.95 & 10883 & 74.21 \\
\hline & Using & 4.30 & 2.11 & 3058 & 25.79 \\
\hline \multirow[t]{11}{*}{ Region } & Tigray & 4.75 & 2.04 & 1436 & 6.90 \\
\hline & Afar & 5.64 & 4.59 & 888 & 0.73 \\
\hline & Amhara & 4.01 & 2.09 & 1511 & 23.41 \\
\hline & Oromia & 4.09 & 2.92 & 1684 & 36.10 \\
\hline & Somali & 10.59 & 4.52 & 1093 & 2.50 \\
\hline & Benshangul G. & 5.01 & 2.50 & 1012 & 1.03 \\
\hline & SNNPE & 4.91 & 2.19 & 1712 & 21.71 \\
\hline & Gambela & 4.55 & 2.40 & 974 & 0.30 \\
\hline & Harari & 4.15 & 2.55 & 816 & 0.25 \\
\hline & Addis Ababa & 3.56 & 1.87 & 1786 & 6.50 \\
\hline & Dire Dawa & 5.41 & 3.10 & 1029 & 0.59 \\
\hline \multirow[t]{2}{*}{ Place of Residence } & Urban & 3.84 & 2.18 & 5012 & 23.40 \\
\hline & Rural & 4.64 & 2.89 & 8929 & 76.60 \\
\hline \multirow[t]{5}{*}{ Wealth index } & Poorest & 5.50 & 3.68 & 3189 & 15.60 \\
\hline & Poorer & 4.60 & 2.77 & 1787 & 17.58 \\
\hline & Middle & 4.47 & 2.63 & 1790 & 19.07 \\
\hline & Richer & 4.28 & 2.51 & 1825 & 19.83 \\
\hline & Richest & 3.89 & 2.18 & 5350 & 27.92 \\
\hline \multirow[t]{2}{*}{ Women's working } & Not working & 4.54 & 2.85 & 8813 & 66.34 \\
\hline & Working & 4.28 & 2.57 & 5128 & 33.66 \\
\hline \multirow[t]{4}{*}{ Women's education } & No Education & 5.21 & 3.21 & 5827 & 45.02 \\
\hline & Primary & 3.95 & 2.30 & 4801 & 36.36 \\
\hline & Secondary & 3.57 & 1.73 & 2151 & 12.47 \\
\hline & Higher & 3.63 & 1.73 & 1162 & 6.14 \\
\hline \multirow{6}{*}{ Religion } & Orthodox & 3.99 & 2.10 & 5855 & 43.54 \\
\hline & Catholic & 3.59 & 2.33 & 86 & 0.76 \\
\hline & Protestant & 4.50 & 2.35 & 2631 & 24.43 \\
\hline & Muslim & 5.06 & 3.60 & 5229 & 30.04 \\
\hline & Traditional & 5.11 & 4.28 & 75 & 0.68 \\
\hline & Other & 6.29 & 3.62 & 65 & 0.55 \\
\hline \multirow{3}{*}{ Marital status } & Single & 3.47 & 2.16 & 4015 & 27.44 \\
\hline & Married & 4.94 & 2.89 & 8321 & 62.25 \\
\hline & Separated & 4.10 & 2.63 & 1605 & 10.31 \\
\hline Husband's Education & No Educ & 5.30 & 3.22 & 3659 & 28.02 \\
\hline
\end{tabular}




\begin{tabular}{llllrr}
\hline Variable & Category & Mean & Std. Dev. & Obs. & Percent \\
\hline & Primary & 4.85 & 2.62 & 2702 & 23.84 \\
\cline { 2 - 6 } & Secondary & 4.22 & 2.33 & 1127 & 6.44 \\
\cline { 2 - 5 } & Higher & 4.13 & 2.26 & 965 & 4.84 \\
\cline { 2 - 5 } & Don't know & 4.09 & 3.29 & 75 & 0.41 \\
\hline Husband's Work & Not working & 5.77 & 3.56 & 837 & 4.68 \\
& Working & 4.86 & 2.81 & 7569 & 58.20 \\
\cline { 2 - 5 } & Don't know & 4.73 & 3.07 & 122 & 0.67 \\
\hline
\end{tabular}

Table 2 The results of over-dispersion test after fitting a Poisson regression

\begin{tabular}{llclc}
\hline Statistics & Value & Degrees of freedom & Value/Deg. Freedom & P-value \\
\hline Deviance test statistics & 20712.96 & 13925 & 1.4874 & 0.0000 \\
Pearson Chi-square statistic & 16592.95 & 13925 & 1.1915 & 0.0000 \\
\hline
\end{tabular}

Table 3 Likelihood ratio test value for multilevel negative binomial regression model

\begin{tabular}{rc}
\hline \multirow{2}{*}{ Selection criteria } & \multicolumn{2}{c}{ Regression model } \\
\cline { 2 - 2 } & Negative Binomial \\
\hline LRT & 116.7 \\
\hline
\end{tabular}

Table 4 Comparison of multilevel negative binomial regression modes

\begin{tabular}{rrccc}
\hline & \multicolumn{4}{c}{ Multilevel Negative Binomial Regression Model } \\
\cline { 2 - 5 } $\begin{array}{r}\text { Selection } \\
\text { criteria }\end{array}$ & $\begin{array}{r}\text { Random Intercept only } \\
\text { model }\end{array}$ & $\begin{array}{c}\text { Random intercept } \\
\text { model }\end{array}$ & $\begin{array}{c}\text { Random intercept } \\
\text { model }\end{array}$ & coefficients \\
\hline Log likelihood & -33352.45 & -32246.055 & -32333.4 \\
AIC & 66710.9 & 64566.11 & 64750.8 \\
BIC & 66733.53 & 64845.19 & 65067.6 \\
\hline
\end{tabular}

Table 5 Results of Random Intercept Negative Binomial model for desired number of children. 
[95\% CI for IRR]

\begin{tabular}{llllllll} 
Parameter & Coef. & Std. Err. & Z & & IRR & Lower & Upper \\
\hline $\begin{array}{l}\text { Women's Age (Ref. 15- } \\
19)\end{array}$ & & & & & & & \\
$20-24$ & 0.0132747 & 0.018461 & 0.72 & 0.472 & 1.013363 & 0.9773521 & 1.050701 \\
$25-29$ & 0.0667253 & 0.0204436 & 3.26 & 0.001 & 1.069002 & 1.027015 & 1.112705 \\
$30-34$ & 0.0945112 & 0.0224048 & 4.22 & 0.000 & 1.099122 & 1.051901 & 1.148462 \\
$35-39$ & 0.1939074 & 0.0231183 & 8.39 & 0.000 & 1.213984 & 1.160205 & 1.270256 \\
$40-44$ & 0.2534015 & 0.0251108 & 10.09 & 0.000 & 1.2884 & 1.226525 & 1.353397 \\
$45-49$ & 0.2652772 & 0.0268138 & 9.89 & 0.000 & 1.303792 & 1.237042 & 1.374144
\end{tabular}

Household head (Ref.

Male)

Female

0.0766677

$0.0136964-5.60$

$0.000 \quad 1.079683$

1.051085

1.109059

Living children (Ref. No)

Yes

$\begin{array}{lllllll}0.0231238 & 0.0203587 & 1.14 & 0.256 & 1.023393 & 0.9833614 & 1.065055\end{array}$

Contraception using

(Ref. No)

Yes

$$
\begin{array}{lllll}
-0.0845915 & 0.012204 & -6.93 & 0.000 & 0.9188875
\end{array}
$$

0.897169

0.9411318

Place of residence (Ref. urban)

Rural

$$
0.0079402 \quad 0.0202275 \quad 0.39
$$

$0.695 \quad 1.007972$

0.9687923

1.048736

Wealth index (Ref. poorest)

Poorer

$-0.1407077$

$0.0162564 \quad-8.66$

$0.000 \quad 0.8687432$

0.8414997

0.8968688

Middle

$-0.1550731$

$0.0162146-9.56$

$0.000 \quad 0.8563526$

0.8295656

0.8840045

Richer

$-0.1688103$

$0.0165373-10.21$

$0.000 \quad 0.8446691$

0.8177302

0.8724955

Richest

$-0.1530698$

$0.0216186-7.08$

0.000

0.8580698

0.8224714

0.895209

Women employment

(Ref. Not employed)

Working

$$
-0.010904 \quad 0.0109236-1.00
$$

0.318

0.9891553

0.9682026

1.010561

Women's education (Ref. NO Edu.)

Higher

Secondary

Primary

$\begin{array}{ccc}-0.0644679 & 0.0284637 & -2.26 \\ -0.0844236 & 0.0208422 & -4.05 \\ -0.0919283 & 0.0132575 & -6.93\end{array}$

0.024

0.9375662

0.8866936

0.9913575

Religion (Ref. Orthodox )

Catholic

$0.000 \quad 0.9190418$

0.8822555

0.957362

$0.000 \quad 0.9121705$

0.8887738

0.9361831 
[95\% CI for IRR]

\begin{tabular}{|c|c|c|c|c|c|c|c|}
\hline Parameter & Coef. & Std. Err. & $\mathbf{Z}$ & & IRR & Lower & Upper \\
\hline Protestant & 0.1080062 & 0.012775 & 8.45 & 0.000 & 1.114055 & 1.086507 & 1.142301 \\
\hline Muslim & 0.1488404 & 0.0121185 & 12.28 & 0.000 & 1.160488 & 1.133249 & 1.188381 \\
\hline Traditional & 0.0593275 & 0.0564141 & 1.05 & 0.293 & 1.061123 & .9500486 & 1.185183 \\
\hline Other & 0.2726313 & 0.0589043 & 4.63 & 0.000 & 1.313416 & 1.170207 & 1.47415 \\
\hline $\begin{array}{l}\text { Marital status (Ref. } \\
\text { Single ) }\end{array}$ & & & & & & & \\
\hline Married & 0.1826926 & 0.0578365 & 3.16 & 0.002 & 1.200445 & 1.071795 & 1.344538 \\
\hline Separated & 0.109312 & 0.0359377 & 3.04 & 0.002 & 1.11551 & 1.039641 & 1.196916 \\
\hline \multicolumn{8}{|l|}{$\begin{array}{l}\text { Husband's education (No } \\
\text { Edu) }\end{array}$} \\
\hline Primary & 0.0069265 & 0.0137226 & 0.50 & 0.614 & 1.006951 & 0.9802287 & 1.034401 \\
\hline Secondary & -0.0241666 & 0.0233765 & -1.03 & 0.301 & 0.9761231 & 0.9324091 & 1.021887 \\
\hline Higher & -0.0242655 & 0.0284279 & -0.85 & 0.393 & 0.9760265 & 0.9231319 & 1.031952 \\
\hline Don't know & -0.1738741 & 0.0778496 & -2.23 & 0.026 & 0.8404027 & 0.7214757 & 0.9789333 \\
\hline \multicolumn{8}{|l|}{$\begin{array}{l}\text { Husband's employment } \\
\text { (Not employed) }\end{array}$} \\
\hline Working & -0.0663931 & 0.0215762 & -3.08 & 0.002 & 0.9357629 & 0.8970159 & 0.9761837 \\
\hline Don't know & -0.0945897 & 0.0620669 & -1.52 & 0.128 & 0.9097462 & 0.8055432 & 1.027429 \\
\hline Family size & 0.0199469 & 0.0022731 & 8.78 & 0.000 & 1.020147 & 1.015612 & 1.024702 \\
\hline Age at first marriage & -0.0069415 & 0.0014893 & -4.66 & 0.000 & 0.9930825 & 0.990188 & 0.9959855 \\
\hline _cons & 1.437436 & 0.0603361 & 23.82 & 0.000 & 4.20989 & 3.740352 & 4.738369 \\
\hline /lnalpha & -2.355457 & 0.0424003 & -55.55 & 0.000 & -2.355457 & -2.43856 & -2.272354 \\
\hline \multicolumn{8}{|l|}{ Region } \\
\hline var(_cons) & 0.0083395 & 0.0075838 & & & 0.0083395 & 0.001403 & 0.0495692 \\
\hline
\end{tabular}

\section{Figures}




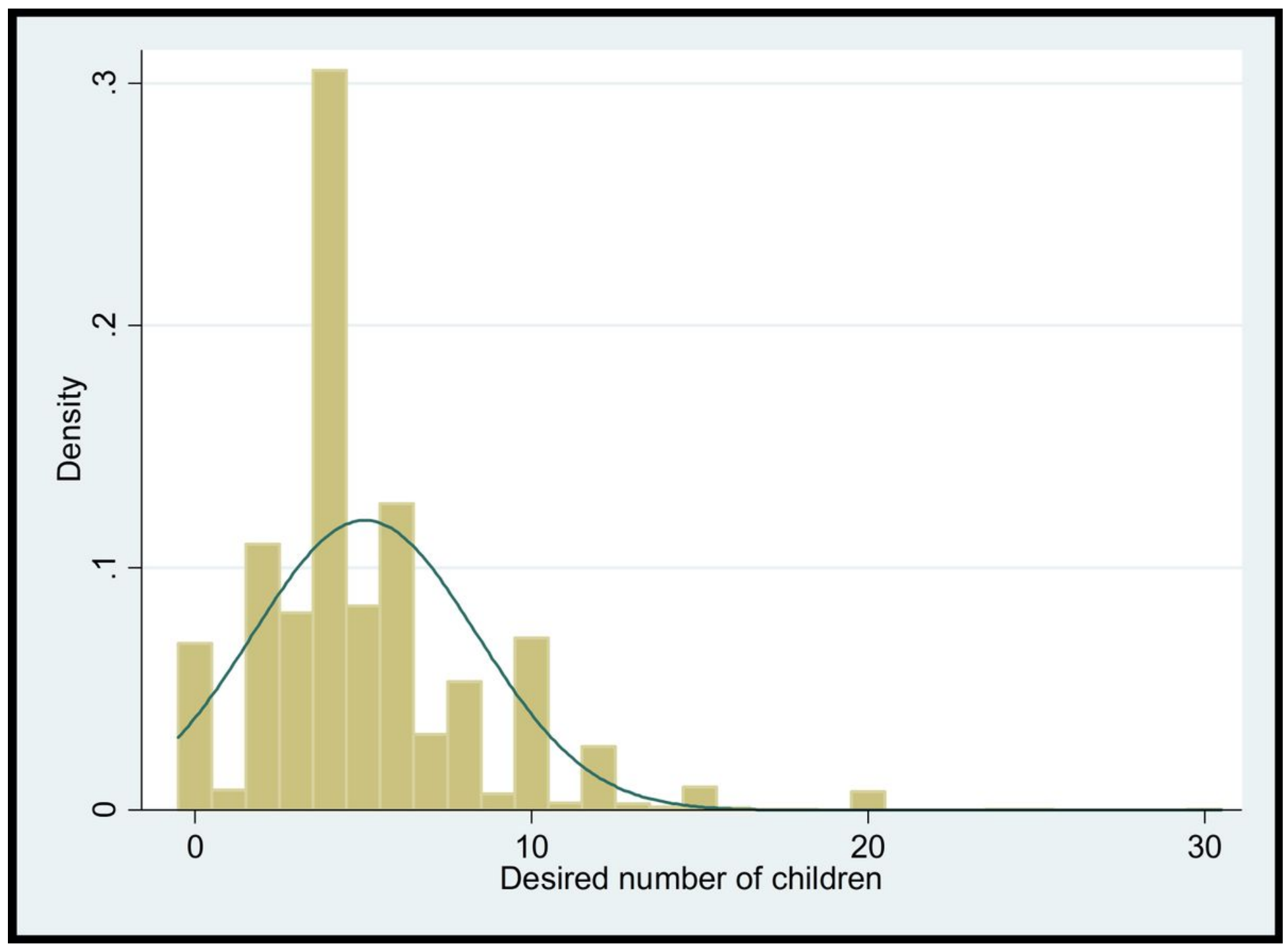

Figure 1

Histogram for desired number of children by women weighted data 